\title{
Conduction in unmyelinated fibres in experimental neuropathy ${ }^{1}$
}

\author{
A. P. HOPKINS ${ }^{2}$ AND E. H. LAMBERT \\ From the Department of Physiology, Mayo Graduate School of Medicine, \\ Rochester, Minnesota, U.S.A.
}

SUMMARY Conduction velocity of autonomic unmyelinated fibres has been measured in the cervical sympathetic trunk of normal rats, and in rats intoxicated by acrylamide or by isoniazid. The mean maximal conduction velocity in nerves from normal rats is $2.0 \mathrm{~m} / \mathrm{sec}$. There is no significant reduction in velocity of the unmyelinated fibres in nerves from intoxicated rats, although histological studies of the sural nerve confirmed severe degeneration of myelinated fibres in the same animals. It is shown that the amplitude of the compound nerve action potential is proportional to the resistance between the recording electrodes. If this is taken into account, there is no reduction in the amplitude of the monophasic action potential of unmyelinated fibres recorded from the cervical sympathetic trunk of intoxicated rats. The amplitude of the A component of the sural nerve compound action potential is markedly reduced in rats intoxicated by acrylamide or by isoniazid, but there is no significant reduction in the amplitude of the $\mathbf{C}$ component in the same nerve. It is concluded that in the rat an insignificant number of unmyelinated fibres of autonomic or dcrsal root origin are affected in the neuropathy produced by acrylamide or isoniazid. The relevance of these findings to human neuropathies is discussed.

In the last 10 years there have been a number of reports about the changes in conduction velocity in various experimental neuropathies (for references see Gilliatt, 1969). Information has been obtained from these studies which is probably applicable to the naturally occurring neuropathies of man. These reports refer only to changes in conduction in myelinated fibres.

Recent studies by Buchthal (1971) have shown that it is possible in special circumstances to record unmyelinated (C) fibre compound action potentials in vivo in man. Moreover, the work of Dyck and Lambert (1966) has shown that useful information can be obtained by recording in vitro from excised human sural nerves. In this situation, $\mathrm{C}$ fibre action potentials can be easily recorded from the normal sural nerve, and their absence has been correlated with absence of unmyelinated fibres on electron microscopy in certain neuropathies (Dyck and Lambert, 1969).

\footnotetext{
1 Supported by a grant from the National Fund for Research into Crippling Diseases, London, and the Louis W. and Maud Hill Family Foundation, St. Paul, Minn. Travelling expenses for A. P. Hopkins were met by a grant from the Wellcome Trust.

2 Present address: Department of Neurology, St. Bartholomew's Hospital, West Smithfield, London, EC1A 7BE.
}

There are about three and a half times as many unmyelinated fibres as myelinated in the human sural nerve (Ochoa and Mair, 1969a) and probably approximately the same proportion in other cutaneous nerves. Information is therefore required about changes in unmyelinated fibres in peripheral neuropathies.

Acrylamide and isoniazid both produce peripheral neuropathy in man (Fullerton, 1969; Jones and Jones, 1953). Both damage myelinated fibres severely. Ultrastructural changes have been reported in unmyelinated fibres in isoniazid neuropathy in man (Ochoa, 1970) and in the rat (Schröder, 1970).

The present paper reports observations on conduction in unmyelinated fibres in rats, in which a severe peripheral neuropathy was induced by either acrylamide or isoniazid.

\section{METHODS}

Sprague-Dawley rats aged 6 months were fed a commercial diet, with which had been mechanically mixed either acrylamide $0.3 \mathrm{~g} / \mathrm{kg}$ (300 p.p.m.approximate intake $15 \mathrm{mg} / \mathrm{kg} / \mathrm{day}$ ), or isoniazid $3 \mathrm{~g} / \mathrm{kg}$ (3,000 p.p.m. - approximate intake $150 \mathrm{mg}$ / 
$\mathrm{kg}$ /day). These are doses similar to those employed by Fullerton and Barnes (1966) and Cavanagh (1967) in their observations on myelinated fibres of rats intoxicated by these substances.

Conduction velocity of autonomic unmyelinated fibres was measured in the right cervical sympathetic trunk in vitro at $37^{\circ} \mathrm{C}$, using the length from the subclavian artery to the superior cervical ganglion. Foley and Dubois (1940) and Dyck and Hopkins (1972) have shown that this nerve is almost totally unmyelinated, so that no confusion can arise from slowed conduction in damaged myelinated fibres. The sympathetic trunk was stimulated supramaximally by shocks of 10 to $100 \mathrm{~V}$ and of $0.2 \mathrm{msec}$ duration. Action potentials were recorded from pairs of freshly chlorided fine silver electrodes approximately 4,8 , and $12 \mathrm{~mm}$ distal to the stimulating cathode, the exact distance being measured with a microscope and measuring eyepiece. The action potential recorded at $12 \mathrm{~mm}$ was monophasic, as the second of this pair of electrodes lay in $1 \%$ procaine. Details of the construction of the chamber, and of the precautions taken to prevent procaine diffusing down the nerve are reported elsewhere (Hopkins and Lambert, 1972).

Observations were also made on the left sural nerve of the rats, using the length from knee to $4 \mathrm{~mm}$ above the os calcis. The great majority of unmyelinated fibres in this nerve are of dorsal root origin. No attempt was made to measure velocity of conduction in this nerve, but attention was directed to the amplitude of the $\mathrm{A}$ and $\mathrm{C}$ components of the compound action potential. The sural nerve was stimulated at a point corresponding to $20 \mathrm{~mm}$ above the os calcis, and a monophasic action potential was recorded $12 \mathrm{~mm}$ distal to this.

Action potentials were recorded on photographic film using conventional recording equipment, the half amplitude frequency response being set at $0 \cdot 1$ and $10,000 \mathrm{~Hz}$ for $A$ potentials, and at $0 \cdot 1$ and 2,000 $\mathrm{Hz}$ for $\mathrm{C}$ potentials. Twenty-five faint traces of the latter were superimposed on the film for ease of measurement of the inflexion of the response, which was used for calculation of the velocity of the cervical sympathetic fibres.

The amplitude of the monophasic action potential is dependent on the shunting resistance between the recording electrodes, as well as on the number of active fibres contributing to the potential. As this shunting resistance is dependent on the thickness of the nerve, the extent to which it is cleaned, and the quantity of Tyrode's solution clinging to the nerve, it is necessary to monitor the inter-electrode resistance after recording each potential. The voltage drop across these electrodes, using a pulse derived from a constant current source, was compared with the voltage drop across a standard resistor in series with the electrode, and hence the inter-electrode resistance was calculated.

\section{RESULTS}

\section{THE CLINICAL ILLNESS}

a. ACRYLAMIDE Weakness of the hind-limbso was first noted at four weeks. At eight weeks ${ }_{\text {कD }}^{\top 0}$ there was marked weakness of the hind-limbso which were dragged passively along the floor There was also some weakness of the fore-limbs, and the tail was flaccid, although some move $\overrightarrow{\vec{F}}$ ment was still observed. Even though acrylamide was continued for up to a further 18 weeks, noc major change in this pattern of weakness was observed, although a number of rats died.

b. ISONIAZID Clinical signs were much less apparent in these animals. The only sign noted after administration for as long as 28 weeks was ${ }^{\circ}$ a tendency for the hind-feet to evert while running. The animals could, however, still stando on their hind-legs to sniff around, though they tended to fall over.

\section{HISTOLOGICAL OBSERVATIONS}

Longitudinal sections and teasing of the right sural nerve at necropsy confirmed severe degen-o eration of myelinated fibres in both groups rats.

\section{ELECTROPHYSIOLOGICAL OBSERVATIONS}

a. CERVICAL SYMPATHETIC TRUNK Measure N̦ ments of conduction velocity in normal rats aged 10 months and intoxicated rats are shown in Table 1. There is no significant slowing of con- ㅡㅡㅁ duction in the intoxicated rats.

\section{TABLE 1}

CONDUCTION VELOCITY OF FASTEST UNMYELINATED FIBRES IN THE CERVICAL SYMPATHETIC TRUNK OF NORMAL AND INTOXICATED RATS*

\begin{tabular}{lccc}
\hline & $\begin{array}{c}\text { Rats } \\
(\text { no. })\end{array}$ & $\begin{array}{c}\text { Mean conduction } \\
\text { velocity } \\
(\mathrm{m} / \mathrm{sec})\end{array}$ & $\begin{array}{c}\text { Mean duration of } \\
\text { intoxication } \\
(\text { weeks })\end{array}$ \\
\hline $\begin{array}{l}\text { Normal } \\
\text { Acrylamide }\end{array}$ & 14 & $2 \cdot 02(1 \cdot 69-2 \cdot 32)$ & $14(9-28)$ \\
Isoniazid & 7 & $2.00(1 \cdot 77-2 \cdot 32)$ & $24(13-28)$ \\
\hline * Ranges are in parentheses. & $1.93(1 \cdot 72-2 \cdot 56)$ &
\end{tabular}

Figure 1 illustrates typical sympathetic monoN phasic action potentials recorded from a normah rat, and rats intoxicated by acrylamide anф్ isoniazid. Minor variations in the shape of the potential were found in normal animals. Note that the calibration markers indicate that the potential recorded from the normal rat is muclep larger than those recorded from the intoxicatedo 


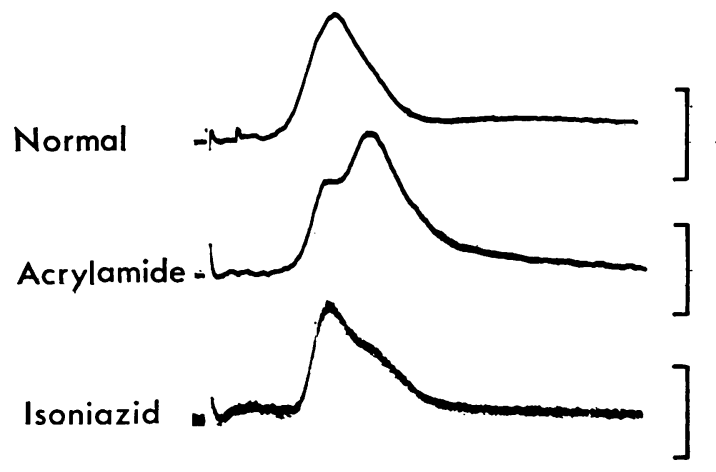

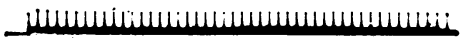

$10 \mathrm{msec}$ rats. This is, however, due only to variations in inter-electrode resistance as shown in Fig. 2. In this Figure the amplitude of the monophasic action potential has been plotted against the inter-electrode resistance. The solid circles are points for the 10 out of the 14 normal animals in which inter-electrode resistance was also measured. The regression line between these points has been drawn, and the dotted lines represent \pm two standard errors of this line. The open squares, representing the values for the acrylamide rats, and the open triangles, representing the isoniazid values, all fall within the dotted lines, indicating that there is no signifi-
FIG. 1 Monophasic action potentials recorded from the cervical sympathetic trunk of a normal rat, and of rats intoxicated by acrylamide or by isoniazid. Conduction distance $12 \cdot 1$ to $12 \cdot 3 \mathrm{~mm}$.
25
$\mu V$ cant diminution in the amplitude of the monophasic action potential.

b. SURAL NERVE Figure 3 shows monophasic potentials recorded from myelinated and unmyelinated fibres $(\mathrm{A} \alpha, \mathrm{A} \delta$, and $\mathrm{C}$ action potentials). Records have been chosen from nerves in which the inter-electrode resistance was approximately equal in each case. Note the gross diminution in amplitude of the A component of the action potential in rats intoxicated both by acrylamide and by isoniazid, though the amplitude of the $\mathbf{C}$ action potential is preserved. That this is the case for all rats is indicated by Figs 4 and 5. In Fig. 4 the amplitude

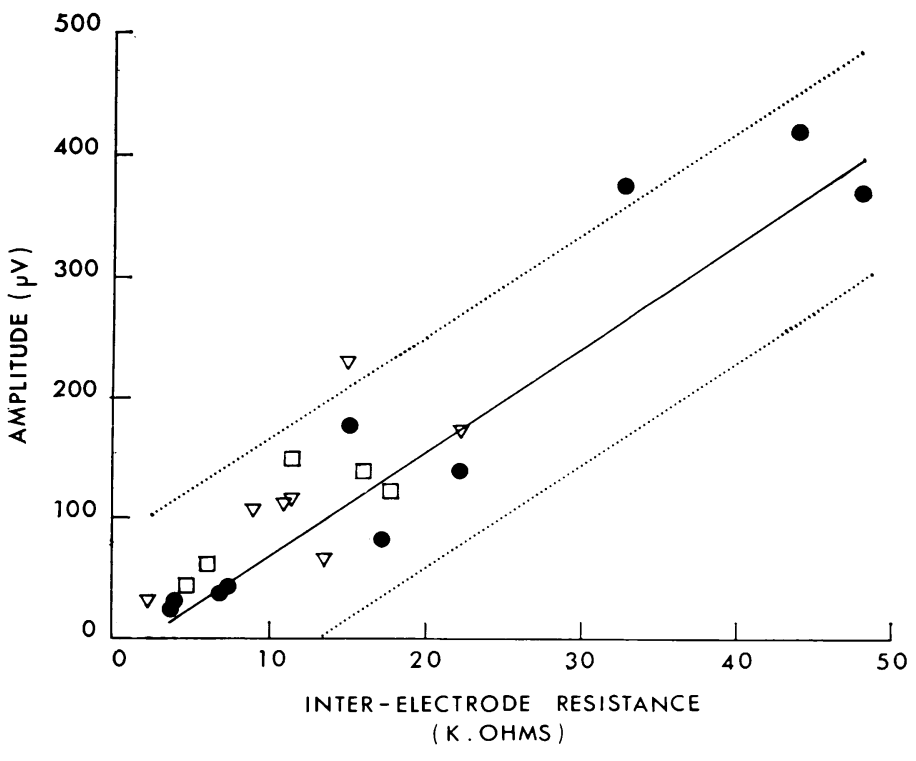

FIG. 2. Amplitude of monophasic action potentials recorded from the cervical sympathetic trunk of normal rats (०), and of rats intoxicated by acrylamide ( $\square$ ) or by isoniazid $(\nabla)$, plotted against the resistance between the recording electrodes. Conduction distances are $12 \cdot 1$ to $12 \cdot 3 \mathrm{~mm}$. The calculated regression line for the normal rats has been drawn, $\pm 2 S E$. 


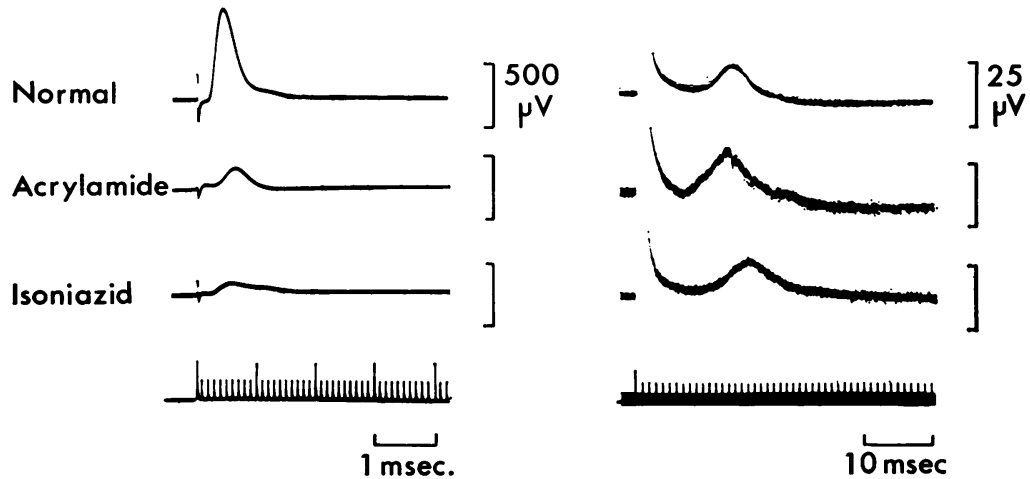

FIG. 3. Monophasic action potentials recorded from the sural nerve of normal and intoxicated rats at a point $8 \mathrm{~mm}$ above the os calcis. The stimulus was twice that necessary to evoke a maximal response of myelinated fibres (left hand column), and of unmyelinated fibres (right hand column).

of the A component has been plotted against the inter-electrode resistance, the symbols indicating the same groups of animals as in Fig. 2. The regression line \pm two standard errors has been drawn for the normal animals. All values for nerves from rats examined nine to 26 weeks (mean 15 weeks) after beginning acrylamide fell well below the normal range of amplitude of the A component. Five out of the eight values for rats intoxicated by isoniazid for 13 to 27 weeks (mean 25 weeks) also fell below the normal range. The three values within the normal range are those obtained from the rats intoxicated for the shortest time.

In Fig. 5 the amplitude of the $\mathrm{C}$ component of the sural compound nerve action potential has been plotted against the inter-electrode resistance, the symbols indicating the same groups of animals as in Figs. 2 and 4. The amplitudes of the C component of the potentials recorded from intoxicated animals are not significantly different from those of the normal animals.

Measurements of velocity of myelinated or unmyelinated fibres were not attempted in the sural nerve. However, Table 2 shows the mean latencies of inflexion of $\mathrm{A}$ and $\mathrm{C}$ components of the compound nerve action potential recorded 12.1 to $12.3 \mathrm{~mm}$ distal to the stimulating cathode For these records twice the stimulus necessary to evoke a maximal response was used, and potentials were recorded at high amplification using a fast sweep speed. The latency of inflexion of the A component recorded from sural nerves of acrylamide intoxicated rats was more than

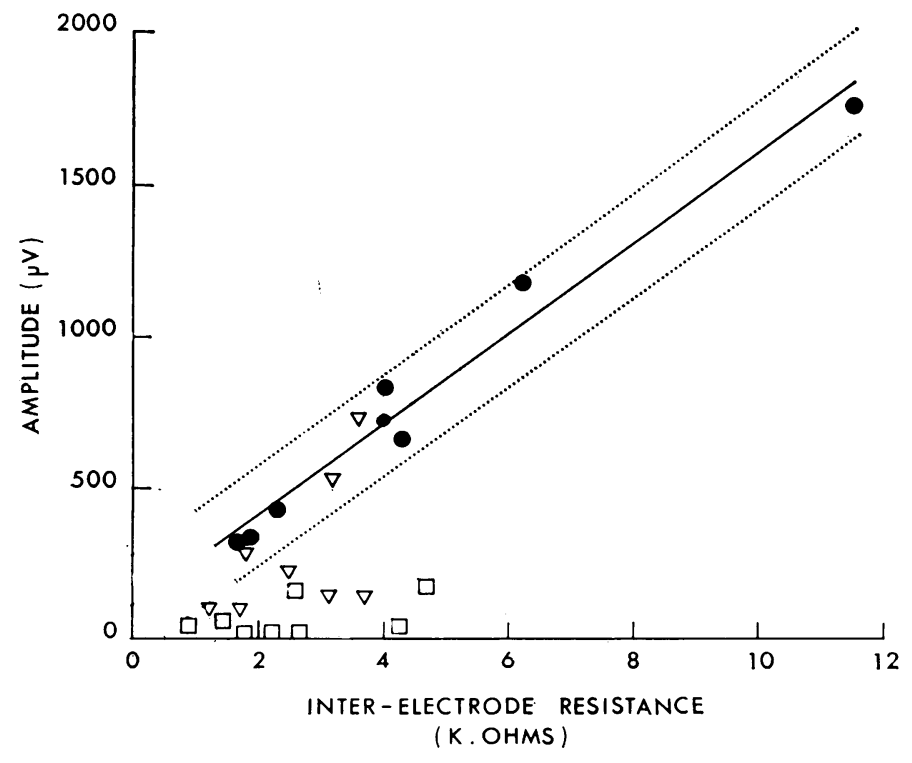

FIG. 4. Amplitude of the A component of the sural nerve action potential of normal rats $(\bullet)$, and of rats intoxicated by acrylamide ( $\square$ ) or by isoniazid $(\nabla)$ plotted against the resistance between the recording electrodes. Conduction distances as in Table 2. The calculated regression line for the normal rats has been drawn, $\pm 2 S E$. 


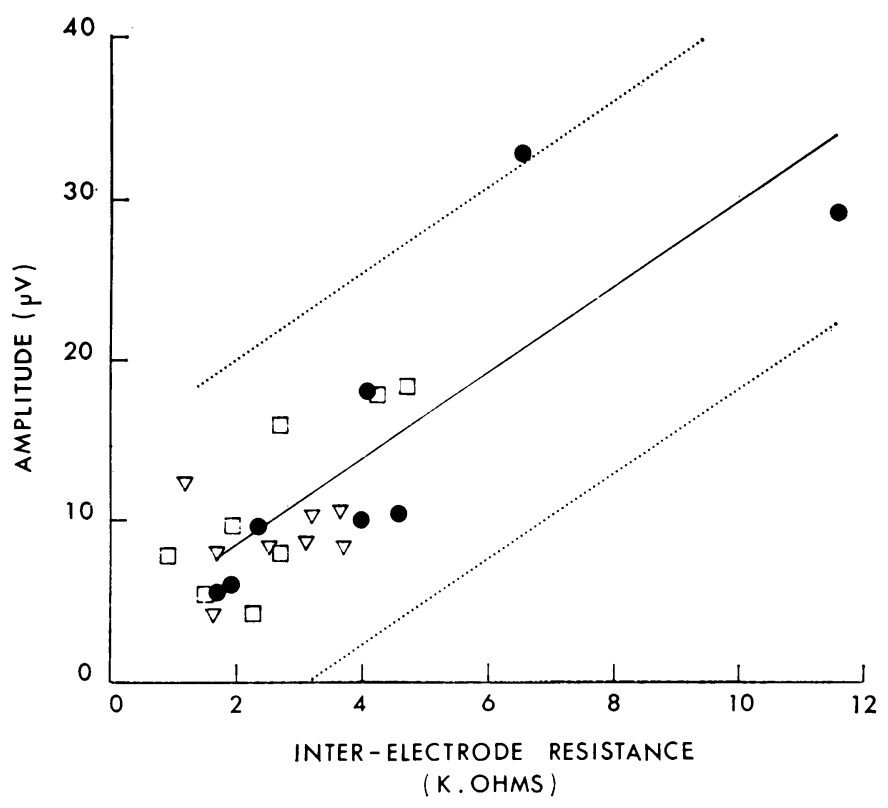

FIG. 5. Amplitude of the $C$ component of the sural nerve action potential of normal rats $(\bullet)$, and of rats intoxicated by acrylamide ( $\square$ ) or by isoniazid $(\nabla)$ plotted against the resistance between the recording electrodes. Conduction distances as in Table 2. The calculated regression line for the normal rats has been drawn, $\pm 2 S E$.
TABLE 2

MEAN LATENCIES OF INFLEXION OF A AND C COMPONENTS OF SURAL NERVE COMPOUND ACTION POTENTIAL, USING TWICE THE STIMULUS WHICH EVOKED A MAXIMAL RESPONSE*

\begin{tabular}{|c|c|c|c|c|}
\hline & $\begin{array}{l}\text { Rats } \\
\text { (no.) }\end{array}$ & $\begin{array}{l}\text { Mean distance } \\
\text { from cathode } \\
(\mathrm{mm})\end{array}$ & $\begin{array}{c}\text { A component } \\
\text { latency } \\
(\mathrm{msec})\end{array}$ & $\begin{array}{c}\text { C component } \\
\text { latency } \\
(\mathrm{msec})\end{array}$ \\
\hline $\begin{array}{l}\text { Normal } \\
\text { Acrylamide } \\
\text { Isoniazid }\end{array}$ & $\begin{array}{l}8 \\
9 \\
8\end{array}$ & $\begin{array}{ll}12 \cdot 25 & (0 \cdot 09) \\
12 \cdot 15 & (0 \cdot 18) \\
12 \cdot 26 & (0 \cdot 14)\end{array}$ & $\begin{array}{l}0.20 \quad(0.08) \\
0.45 \dagger(0.15) \\
0.21 \quad(0.05)\end{array}$ & $\begin{array}{ll}8.8 & (1 \cdot 1) \\
8.1 & (1.3) \\
8.8 & (1.7)\end{array}$ \\
\hline
\end{tabular}

* Standard deviations are in parentheses.

$\dagger \mathrm{P}<0.005$. No other difference from normal has $\mathrm{P}<0.1$.

twice that from normal rats, or from rats intoxicated by isoniazid. There was no significant difference in the latencies of inflexion of the $\mathrm{C}$ component.

\section{DISCUSSION}

The present study has shown that neither acrylamide nor isoniazid has a detectable effect on conduction velocity of autonomic unmyelinated fibres, or on the amplitude of the unmyelinated fibre compound action potential recorded from the cervical sympathetic trunk, or from the sural nerve. There is no doubt that the myelinated fibres were severely affected as shown by histological examination of the sural nerves, and the marked reduction in amplitude of the $A$ component of the sural nerve action potential. a. ACRYLAMIDE Measurements of diameters of fibres of acrylamide-intoxicated rats and baboons and electrophysiological observations on these animals have shown that acrylamide causes degeneration of fibres of larger diameter and rapid conduction (Fullerton and Barnes, 1966; Hopkins, 1970; Hopkins and Gilliatt, 1971). In the present study the increased latency of the A component of the sural nerve action potential is in accord with this. However, if acrylamide is continued, there is no doubt that degeneration of small myelinated fibres takes place as well. The low amplitudes of myelinated fibre action potentials shown in Fig. 4 indicate that very few myelinated fibres remain. It is surprising that unmyelinated fibres are so totally preserved; since this study was begun this feature has been confirmed by electron microscopic studies on the nerves of acrylamide intoxicated cats (Prineas, 1969). This phenomenon suggests that neuronal metabolism of unmyelinated fibres may be quite different in some respects from that of even small myelinated fibres. It would be interesting to know if acrylamide interferes with axonal transport of tritiated thymidine in unmyelinated fibres, as Pleasure, Mishler and Engel (1970) have shown to occur in myelinated fibres.

As acrylamide causes a 'dying-back' neuropathy (Fullerton and Barnes, 1966; Hopkins, 1970), it might be argued that recordings have not been made at axonal sites sufficiently remote from the neurone. However, the sympathetic 
monophasic action potential was recorded from electrodes only $4 \mathrm{~mm}$ and $1 \mathrm{~mm}$ from the inferior pole of the superior cervical ganglion, and the sural potential from electrodes $8 \mathrm{~mm}$ and $5 \mathrm{~mm}$ proximial to the os calcis - a point at which there was gross degeneration of myelinated fibres.

b. ISONIAZID Isoniazid neuropathy in rats has been studied by a number of authors, notably Schlaepfer and Hagen (1964a, b, c), Cavanagh (1967), and Schroder (1970).

The relative absence of functional disturbance in isoniazid intoxicated rats has been noted by others (for example, Cavanagh, 1967), but histological examination, and the amplitude of the myelinated component of the sural nerve action potential leave no doubt that the rats in the present study were severely affected. The normal latency of inflexion of the A component is in accord with the observation of Cavanagh that reduction in numbers of myelinated fibres affects fibres of all diameters, and not preferentially the fibres of large diameter.

The failure to observe any decrease in the amplitude of the unmyelinated fibre action potential in either the sympathetic trunk or in the sural nerve of rats intoxicated by isoniazid is surprising in view of the recent observations of Ochoa (1970) and Schröder (1970). Ochoa reported quantitative studies on unmyelinated fibres in the sural nerves of five patients with isoniazid neuropathy. In six normal subjects aged under 35 years the mean density of unmyelinated fibres was 27,637 per square millimetre. The mean density of axons devoid of myelin in nerves of the five patients was 19,514. However, it should be noted that the ages of the patients with isoniazid neuropathy ranged from 42 to 70 , with a mean of 57 years. As Ochoa and Mair (1969b) have described evidence of degeneration of unmyelinated fibres with advancing age, it is possible that at least some of the reduction in numbers of axons devoid of myelin could be due to the changes of ageing alone. Schröder (1970) did not undertake quantitative counts of unmyelinated fibres in his studies. In the early stages of degeneration of the myelinated fibres, he notes that the majority of unmyelinated fibres remained intact. However, after two or more weeks it appeared that their number was reduced. Schröder publishes electron micrographs of degenerating unmyelinated fibres.

It is possible that regeneration of unmyelinated fibres could keep pace with the degeneration, and
Ochoa (1970) adduces indirect evidence for this $z$ during the course of isoniazid intoxication in $\stackrel{\overline{2}}{\stackrel{2}{2}}$ man. He found an excess of axons devoid of myelin of around $0.6 \mu$ diameter, which are probably regenerating. However, in two of his 0 five cases, isoniazid has been stopped for many months. A population of fine regenerating fibres would be expected to alter the shape of the compound action potential and there is no evidence of this in the present study.

The present study shows the necessity of $\frac{\bar{\partial}}{\frac{0}{0}}$ measuring the interelectrode resistance if $\vec{\sigma}$ measurements of action potential amplitude are to be meaningful estimates of numbers of fibres contributing to the potential. One of us (E.H.L.) has found that the action potential amplitude recorded from whole human sural nerve biopsies does not differ significantly from the amplitude recorded from fascicular biopsies. Table 3 shows such an example. Presumably the greater conductance of the thicker nerve between the recording electrodes compensates for the larger $\stackrel{\omega}{\circ}$ number of active fibres. Consequently, it appears 을 that a reduction of numbers of fibres in path $\rightarrow$ logical states may be overlooked unless inter $\frac{7}{0}$ electrode resistance, and the diameter of the fascicle or nerve under study, is taken int account.

TABLE 3

AMPLITUDE OF MONOPHASIC C FIBRE ACTION POTENTIALS RECORDED FROM WHOLE HUMAN SURAL NERVE, AND FROM FASCICLES OF SAME NERVE, AND MEASUREMENTS OF INTERELECTRODE RESISTANCE*

\begin{tabular}{lcc}
\hline & $\begin{array}{c}\text { Inter-electrode } \\
\text { resistance } \\
(K \Omega)\end{array}$ & $\begin{array}{c}\text { Amplitude of } \\
\text { C fibre potential } \\
(\mu V)\end{array}$ \\
\hline Whole nerve & 5 & 67 \\
2 fascicles & 18 & 53 \\
2 fascicles & 20 & 77 \\
1 fascicle & 50 & 65 \\
1 fascicle & 61 & 65 \\
1 fascicle & 47 & 65 \\
\hline
\end{tabular}

* Distance between electrodes $20 \mathrm{~mm}$.

The experiments reported in this paper suggest that neither acrylamide nor isoniazid affects significant numbers of unmyelinated fibres, at least with the dosage schedule and the species studied. If one adds to this observation the brief sentence of Eliasson (1964) that the C action potential did not appear to be altered in the vagus nerve of diabetic rats, and the observations 
of normal $\mathrm{C}$ action potentials in the sural nerves of cases of peroneal muscular atrophy, acute infective polyneuritis and Friedreich's ataxia (Dyck and Lambert, 1966; Lambert, unpublished observations), the present evidence suggests that unmyelinated fibres must seldom be affected in significant numbers in peripheral neuropathies. However, there is little doubt that sudomotor failure in diabetes is due to a failure of visceral efferents (Bárány and Cooper, 1956). Amyloid neuropathy (Dyck and Lambert, 1969) and the Riley-Day syndrome (Aguayo, Nair, and Bray, 1971) are the known exceptions in which the predominant disorder seems to lie in the unmyelinated fibres.

\section{REFERENCES}

Aguayo, A. J., Nair, C. P. V., and Bray, G. M. (1971). Peripheral nerve abnormalities in the Riley-Day syndrome. Archives of Neurology, 24, 106-116.

Bárány, F. R., and Cooper, E. H. (1956). Pilomotor and sudomotor innervation in diabetes. Clinical Science, 15, 533-540.

Buchthal, F. (1971). Personal communication.

Cavanagh, J. B. (1967). On the pattern of change in peripheral nerves produced by isoniazid intoxication in rats. Journal of Neurology, Neurosurgery, and Psychiatry, 30, 26-33.

Dyck, P. J., and Hopkins, A. P. (1972). Electron microscopic observations on degeneration and regeneration of unmyelinated nerve fibres. Brain (in press).

Dyck, P. J., and Lambert, E. H. (1966). Numbers and diameters of nerve fibres and compound action potential of sural nerve: controls and hereditary neuromuscular disorders. Transactions of the American Neurological Association, 91, 214-217.

Dyck, P. J., and Lambert, E. H. (1969). Dissociated sensation in amyloidosis. Archives of Neurology, 20, 490-507.

Eliasson, S. G. (1964). Nerve conduction changes in experimental diabetes. Journal of Clinical Investigation, 43, 2353-2358.

Foley, J. O., and Dubois, F. S. (1940). A quantitative and experimental study of the cervical sympathetic trunk. Journal of Comparative Neurology, 72, 587-598.
Fullerton, P. M. (1969). Electrophysiological and histological observations on peripheral nerves in acrylamide poisoning in man. Journal of Neurology, Neurosurgery, and Psychiatry, 32, 186-192.

Fullerton, P. M., and Barnes, J. M. (1966). Peripheral neuropathy in rats produced by acrylamide. British Journal of Industrial Medicine, 23, 210-221.

Gilliatt, R. W. (1969). Experimental peripheral neuropathy. In The Scientific Basis of Medicine, Annual Reviews, 1969, Chap. 12, pp. 202-219. Athlone Press: London.

Hopkins, A. P. (1970). The effect of acrylamide on the peripheral nervous system of the baboon. Journal of Neurology, Neurosurgery, and Psychiatry, 33, 805-816.

Hopkins, A. P., and Gilliatt, R. W. (1971). Motor and sensory conduction velocity in the baboon; normal values and changes during acrylamide neuropathy. Journal of Neurology, Neurosurgery, and Psychiatry, 34, 415-426.

Hopkins, A. P., and Lambert, E. H. (1972). Conduction in regenerating unmyelinated fibres. Brain (in press).

Jones, W. A., and Jones, G. P. (1953). Peripheral neuropathy due to isoniazid. Report of two cases. Lancet, i, 1073-1074.

Ochoa, J. (1970). Isoniazid neuropathy in man: quantitative electron microscope study. Brain, 93, 831-850.

Ochoa, J., and Mair, W. G. P. (1969a). The normal sural nerve in man. I. Ultrastructure and numbers of fibres and cells. Acta Neuropathologica, 13, 197-216.

Ochoa, J., and Mair, W. G. P. (1969b). The normal sural nerve in man. 2. Changes in the axons and Schwann cells due to ageing. Acta Neuropathologica, 13, 217-239.

Pleasure, D. E., Mishler, K. C., and Engel, W. K. (1969). Axonal transport of proteins in experimental neuropathies. Science, 166, 524-525.

Prineas, J. (1969). The pathogenesis of dying-back polyneuropathies. Journal of Neuropathology and Experimental Neurology, 28, 598-621.

Schlaepfer, W. W., and Hager, H. (1964a). Ultrastructural studies of INH-induced neuropathy in rats. 1. Early axonal changes. American Journal of Pathology, 45, 209-219.

Schlaepfer, W. W., and Hager, H. (1964b). Ultrastructural studies of INH-induced neuropathy in rats. 2. Alteration and decomposition of the myelin sheath. American Journal of Pathology, 45, 423-433.

Schlaepfer, W. W., and Hager, H. (1964c). Ultrastructural studies of INH-induced neuropathy in rats. 3. Repair and regeneration. American Journal of Pathology, 45, 479-689.

Schröder, J. M. (1970). Die Feinstruktur markloser (Remakscher) Nervenfasern bei der Isoniazid-Neuropathie. Acta Neuropathologica, 15, 156-175. 